\title{
Evaluation of the Impact of an Educational Intervention Focused on Adolescent Vaping Among Rural Middle School Students
}

Holly F. Fitzwater

West Virginia University, hfain@mix.wvu.edu

Follow this and additional works at: https://researchrepository.wvu.edu/etd

Part of the Nursing Commons

\section{Recommended Citation}

Fitzwater, Holly F., "Evaluation of the Impact of an Educational Intervention Focused on Adolescent Vaping Among Rural Middle School Students" (2020). Graduate Theses, Dissertations, and Problem Reports.

7592.

https://researchrepository.wvu.edu/etd/7592

This Problem/Project Report is protected by copyright and/or related rights. It has been brought to you by the The Research Repository @WVU with permission from the rights-holder(s). You are free to use this Problem/Project Report in any way that is permitted by the copyright and related rights legislation that applies to your use. For other uses you must obtain permission from the rights-holder(s) directly, unless additional rights are indicated by a Creative Commons license in the record and/ or on the work itself. This Problem/Project Report has been accepted for inclusion in WVU Graduate Theses, Dissertations, and Problem Reports collection by an authorized administrator of The Research Repository @ WVU. For more information, please contact researchrepository@mail.wvu.edu. 
Evaluation of the Impact of an Educational Intervention Focused on Adolescent Vaping Among Rural Middle School Students

Holly Fain Fitzwater, MSN, APRN, FNP-C

\author{
Capstone submitted \\ to the School of Nursing \\ at West Virginia University \\ in partial fulfillment of the requirements for the degree of \\ Doctorate in Nursing Practice \\ Teresa Ritchie, DNP, APRN, FNP-BC, Faculty of Record \\ Jill Cochran, PhD, APRN, FNP-BC, FAANP \\ Kesheng Wang, PhD, MA, BS \\ Gene Collins, MS
}

Morgantown, WV

2020

Keywords: Vaping, electronic cigarette, e-cigarette, adolescents, students, knowledge, attitudes

Copyright 2020, Holly Fain Fitzwater 


\begin{abstract}
Evaluation of the Impact of an Educational Intervention Focused on Adolescent Vaping Among Rural Middle School Students
\end{abstract}

Holly Fain Fitzwater

According to the Centers for Disease Control (CDC), sixty deaths due to the use of electronic cigarettes or other vaping products have been reported to date. Vaping has become viewed as a safe alternative to traditional cigarette smoking, particularly in the adolescent population. The U.S. Preventive Services Task Force (USPSTF) recommends education by primary care clinicians to prevent initiation of tobacco products among adolescents. In order to combat this health disparity in America's youth, intervention by the nursing profession is necessary. An educational session and interactive game were implemented by a school-based family nurse practitioner in order to change the knowledge and attitudes of students regarding vaping in a rural West Virginia middle school. Data analysis revealed a statistically significant $15.8 \%$ decrease in adolescents who believe vaping is safer than smoking following intervention by the nurse practitioner. Results also determined a statistically significant $27.9 \%$ increase in students' knowledge following the educational session and interactive game. Ongoing education by healthcare professionals is necessary to decrease the morbidity and mortality related to adolescent vaping. 
This project is dedicated to my late grandfather, Harold Fain. 


\section{Acknowledgments}

First and foremost, I praise my Savior, Jesus Christ. I humbly thank Him for blessing me with perseverance and strength to achieve this milestone in my education. I also thank Him for blessing me with wonderful family, friends, faculty members, and colleagues.

My husband, Chris - Thank you for the sacrifices that you made for me to continue my education and reach my goal. On the days that I wanted to give up, you pushed me. You always had faith in me, even in the moments when I didn't have faith in myself. I could not have accomplished this without you. We finally did it! I love you.

My parents, sister, and Aunt Martha - Words cannot express how grateful I am to have had you in my cheering section. Thank you for listening to years of complaints, anxieties, and fears. Each one of you have contributed to my success in some way. I love you all and I am so thankful for each one of you.

Dr. Teresa Ritchie - Thank you for the countless hours that you dedicated to my project. I am grateful to have had you as my Faculty of Record. I truly appreciate the time and support that you have dedicated to my education and nursing career.

Capstone Committee Members - Thank you for the time and efforts that you contributed to my project. I feel very fortunate to have worked with each one of you and look forward to future collaborations. 
Table of Contents

\section{Title and Abstract}

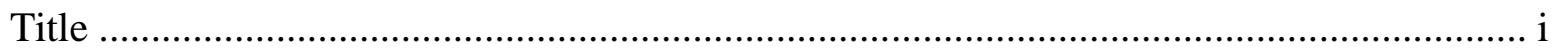

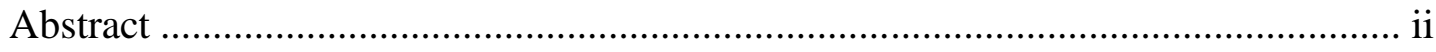

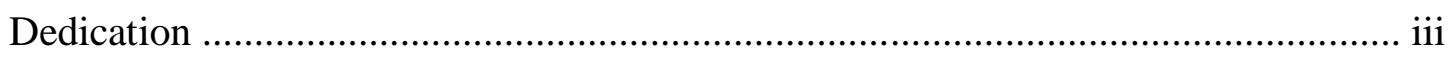

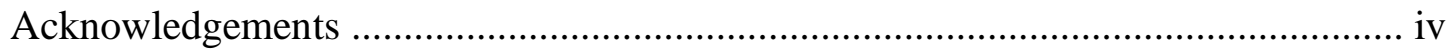

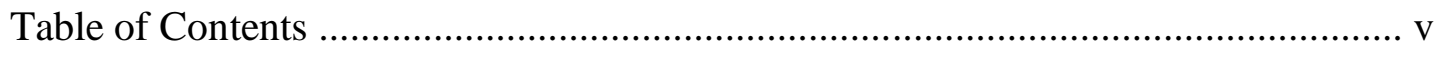

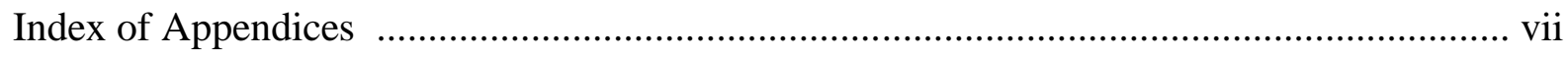

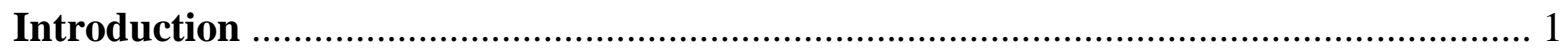

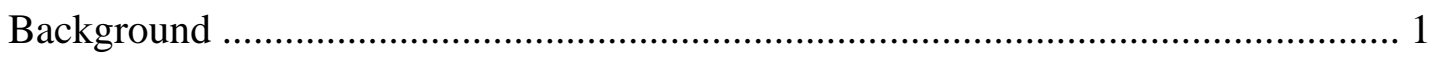

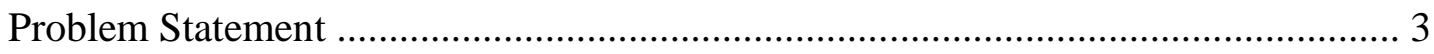

Purpose and Significance of Problem .............................................................. 3

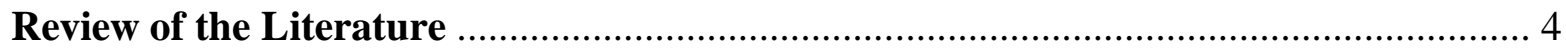

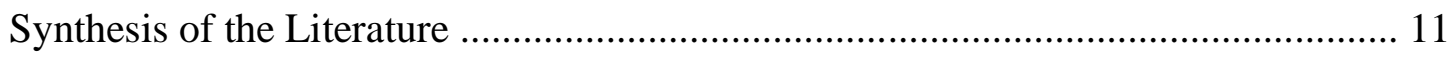

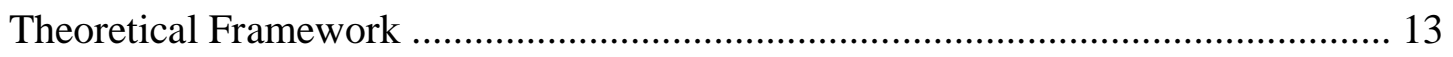

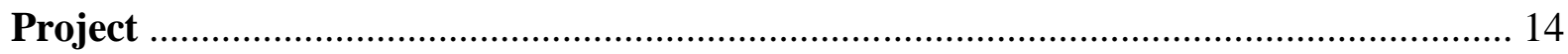

Description and Design of Evidence-Based Project/Intervention Plan ................... 14

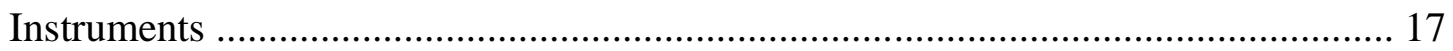

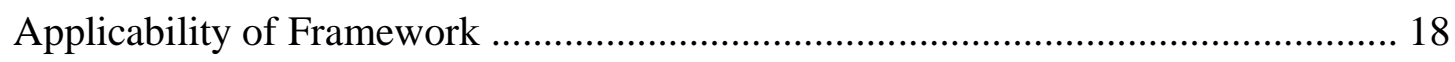

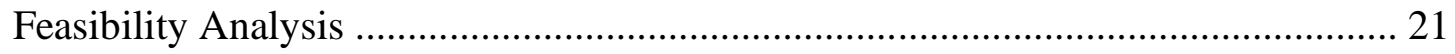

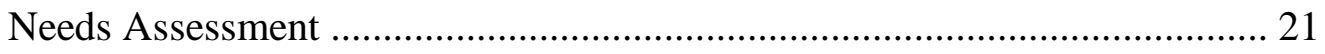

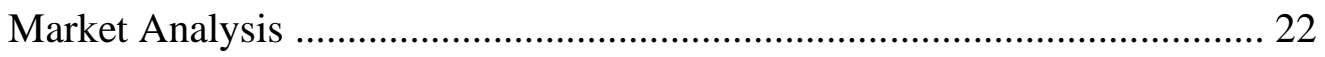

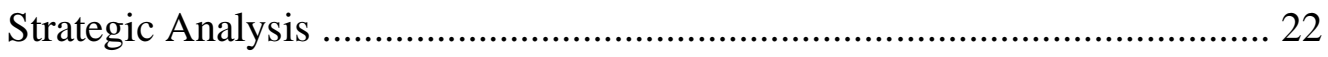




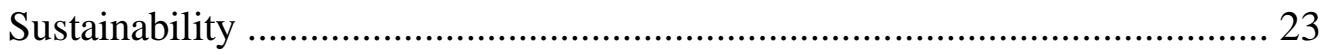

Congruence of Organization's Strategic Plan. ……………........................... 23

Evidence of Key Site Support …………………………............................ 23

Measurable Project Objectives .............................................................................. 24

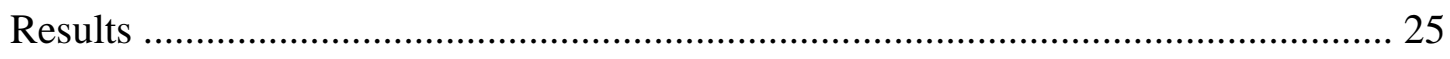

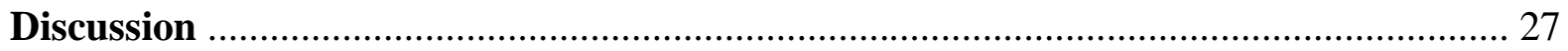

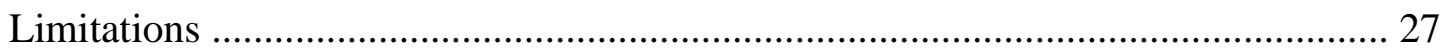

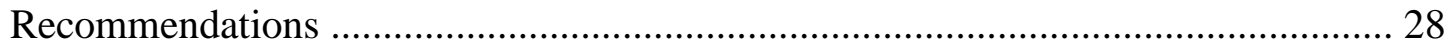

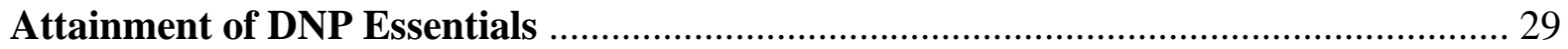

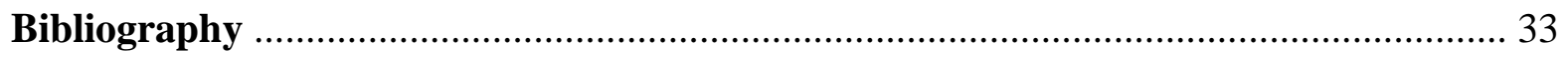

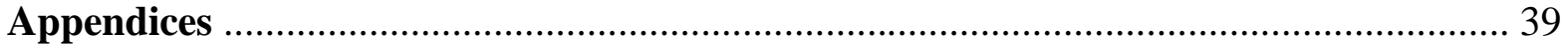




\section{Index of Appendices}

Appendix A: Demographic Questionnaire 39

Appendix B: Pre-Intervention Questionnaire ……………………........................................... 40

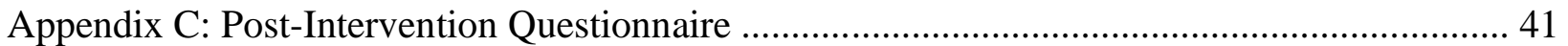

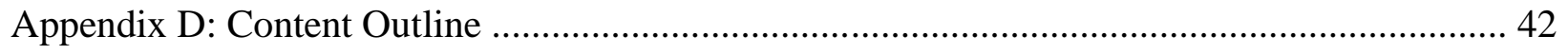

Appendix E: Budget.............................................................................................................. 43

Appendix F: Site Support Verification ..................................................................................... 44

Appendix G: Table 1.Wilcoxon Rank Test Results ................................................................. 45

Appendix H: Table 2. McNemar Chi-Square Test Results .......................................................... 46 
Technology evolves at a quick pace in today's world, which has allowed for safer, more efficient healthcare. However, not all technology has contributed to health promotion and disease prevention. The first electronic cigarette, also referred to as a vape or e-cigarette, was introduced to the United States circa 2006 (Consumer Advocates for Smoke Free Alternatives Association [CASAA], 2019). Many individuals view vapes as safe alternatives to traditional cigarette smoking, resulting in a higher rate of tobacco-associated morbidity and mortality. The prevalence of adolescent vaping is on the rise, becoming the most popular tobacco product among eighth, tenth, and twelfth grade students (Giovacchini, Pacek, McClernon, \& Que, 2017). During the 2018 academic year, multiple vaping devices were confiscated at a middle school in rural West Virginia; therefore, intervention by a school-based family nurse practitioner (FNP) was enlisted to assist in educating the students on the dangers of vaping. This paper discusses an evidence-based intervention directed at changing the knowledge and attitudes of adolescents regarding the dangers of vaping.

\section{Background}

As of January 21, 2020, there were 2,711 reported lung injury cases confirmed nationally due to e-cigarette, or vaping, product use-associated lung injury (EVALI) (Centers for Disease Control and Prevention [CDC], 2020). There have been 60 vaping-related deaths throughout 27 states confirmed thus far (CDC, 2020). Between 2017 and 2018, the number of adolescent students who reported actively using tobacco products increased from 3.6 million to 4.9 million, respectively (Walton et al., 2019). Vaping products are often perceived as being tobacco-free or a safe alternative to traditional tobacco products, but this is a false perception. E-cigarettes have dramatically gained popularity and have been the most popular tobacco product used by youth since 2014 (Walton et al., 2019). Teens are attracted to electronic cigarettes because of their 
appealing technology, sleek designs, and numerous flavorings. As of 2017, more than 15,000 ecigarette flavors were available from online manufacturers (Walton et al., 2019). These factors, as well as targeted marketing to adolescents, have significantly contributed to this growing health concern.

Intervention by FNPs is vital to combat the increasing prevalence of vaping in adolescents. Education by primary care clinicians is recommended to prevent initiation of tobacco products among adolescents (U.S. Preventive Services Task Force [USPSTF], 2019). Results from a systematic review revealed that fewer youth initiate use of tobacco products, including e-cigarettes, when they are recipients of behavioral counseling interventions (USPSTF, 2019). A variety of behavioral counseling interventions, including face-to-face counseling, are deemed effective (USPSTF, 2019). Most research conducted has focused on prevention of cigarette smoking; however, the interventions are applicable for the prevention of vaping because of the similar context and cultural considerations among e-cigarette and traditional cigarette use (USPSTF, 2019).

According to Milicic, DeCicca, Pierard, and Leatherdale (2018), implementing an ecigarette control policy is essential to decrease the prevalence of vaping in school-aged youth. Schools with established policies banning vapes on the facility's property reported less ecigarette use among students compared to schools without policies (Milicic et al., 2018). These policies have the potential to be effective in reducing e-cigarette use in students, indicating the importance for statewide implementation (Milicic et al., 2018). In addition to changing knowledge and attitudes regarding vaping, this quality improvement project will ultimately lead to creation of a vaping-specific policy at the middle school. The project also supported the 
evidence behind the recent legislation to increase the age from 18 to 21 in order to purchase tobacco products.

\section{Problem Statement}

Despite popular belief, most vapes contain nicotine (USPSTF, 2019). Nicotine use during adolescence interferes with brain development, which continues until age 25, and may increase risk for substance abuse during adulthood (CDC, 2019c). According to the National Institute of Health (2018), 10.9\%, or one in ten, eighth grade students reported vaping nicotinecontaining substances within the last year. Intervention within the middle school age group is necessary to target this population and prevent initiation of electronic cigarette use, both now and later, in adolescence or early adulthood. Evidence supports clinician-based education in the adolescent population in order to combat this growing health disparity (USPSTF, 2019).

\section{Purpose and Significance of Project}

A quality improvement project was implemented at a middle school in rural West Virginia. The overarching goal of this project was to educate middle school students on the dangers associated with e-cigarette use, ultimately resulting in a change of knowledge and attitudes. The project consisted of an educational session including a demographic survey, preand post-questionnaires, a 15 minute educational presentation, and an interactive educational game. Prior to the session, students were given the option to complete a pre-test to evaluate their baseline knowledge and attitudes regarding vaping. A post-test was administered after the educational presentation and interactive game. Data was analyzed to determine if students' knowledge and attitudes were impacted by clinician-based education.

This quality improvement project impacted adolescent health by educating middle school students on the dangers of vaping. The goals of the project were to change knowledge and 
attitudes on the severity of e-cigarettes; therefore, preventing and/or reducing the prevalence of adolescent vaping. Future benefits from this educational session include decreasing the prevalence of adolescent vaping, ultimately resulting in decreased morbidity and mortality.

Educating adolescents on the dangers of vaping is essential in order to reduce associated health risks. For example, there is an increased risk of myocardial infarction and irreversible lung damage associated with daily e-cigarette use, despite adolescents' perceptions of less associated harm (Lechner et al., 2018; Walton et al., 2019). Universal education will combat this health disparity and work to achieve the Healthy People 2020 goal to "reduce illness, disability, and death related to tobacco use and secondhand smoke exposure" (Office of Disease Prevention and Health Promotion [ODPHP], 2019).

\section{Review of the Literature}

Two comprehensive literature searches were conducted to obtain the best evidence-based information for the design of this project. The initial literature search was conducted on May 15, 2019 and included the following databases: Academic Search Complete, Cumulative Index to Nursing and Allied Health (CINAHL), Health Source, MEDLINE, Science Direct, and Cochrane Library. The key terms that were utilized for the advanced search included: vaping, electronic cigarette, e-cigarette, middle school students, attitudes, beliefs, and views. Before the application of inclusion and exclusion criteria, 304 articles were yielded. Inclusion criteria included: middle school students, English language, publication between 2013 to 2019, peerreviewed, and nicotine use. Exclusion criteria included: high school students, foreign languages and countries, published before 2013, and cannabis use.

A second literature search was conducted on August 4, 2019 and included the following databases: Academic Search Complete, CINAHL, Health and Psychosocial Instruments, Health 
Source: Nursing/Academic Edition, and MEDLINE. The second literature search was expanded to include the Health and Psychosocial Instruments database. Key search terms included: vaping, electronic cigarette, e-cigarette, teenagers, adolescents, middle school students, education, beliefs, interventions. With this search, there were 18,660 hits. This search was more generalized and included high school students, which resulted in a numerous amount of articles for review. Criteria for inclusion of studies included: children and adolescents under the age of 18, English language, publication between 2013 to 2019, peer-reviewed, and nicotine use. Exclusion criteria included: foreign languages, published before 2013, and cannabis use. A total of 185 articles were yielded after application of the inclusion and exclusion criteria. After critical evaluation, 12 articles were included in the literature review.

Literature consistently supports that electronic cigarette use in the teen population is a health concern and intervention is necessary. Research conducted by Fulton, Gokal, Griffiths, and Wild (2018) recommended vaping-specific education in schools. The cross-sectional experiment revealed that approximately $40 \%$ of students, ages 11 to 16 years, were unaware that e-cigarettes contain nicotine and are addictive (Fulton et al., 2018). Of the nearly 500 participants, $7 \%$ identified as current e-cigarette users in addition to $11.4 \%$ who reported experimenting with vapes in the past (Fulton et al., 2018). An additional longitudinal study conducted in the United Kingdom reported a strong association between vaping and smoking initiation within 12 months among 13 and 14-year-old students (Fulton et al., 2018). According to Fulton et al. (2018), education is necessary to reduce and prevent the incidence of vaping among adolescents.

Statistics obtained from a cross-sectional study in North Carolina students emphasized the prevalence of adolescent vaping and the likelihood of traditional cigarette smoking in the 
future (Kowitt et al., 2019). The purpose of this study was to determine which tobacco products adolescents use first, leading to specific interventions and policies (Kowitt et al., 2019). Per the data collected from the 2017 North Carolina Youth Tobacco Survey (NCYTS) in sixth through twelfth grade students, $33.7 \%$ of adolescents reported that e-cigarettes were their first tried tobacco product (Kowitt et al., 2019). Many adolescents reported experimenting with new tobacco products, such as electronic cigarettes, in addition to traditional cigarettes (Kowitt et al., 2019). According to Kowitt et al. (2019), adolescents exposed to Internet advertisements were more likely to initiate tobacco use with e-cigarettes (0.57 adjusted odds ratios [aORs] and $95 \%$ confidence interval [CI]). Prevention strategies aimed at new and emerging tobacco products are likely to successfully combat the growing epidemic of adolescent vaping.

A 4-year randomized control trial was conducted to determine if the subjects' behavior was impacted by school-based interventions conducted over a 24-month period (Conner et al., 2019). The intervention included biannual education on how to refuse smoking via billboards and handouts (Conner et al., 2019). Homework-based interventions were utilized among the control schools (Conner et al., 2019). According to Conner et al. (2019), adolescents who reported "ever smoked" cigarettes at follow-up was only $15 \%$ for those not currently using cigarettes compared to $42 \%$ who used e-cigarettes at baseline. Cigarette smoking at follow-up was impacted by e-cigarette use at baseline $(\mathrm{p}<0.001)$ (Conner et al., 2019). This study supported the correlation between adolescent e-cigarette use and future cigarette smoking, as well as vaping use in adolescents who have friends who vape (Conner et al., 2019).

According to Bast et al. (2017), successful school-based smoking prevention initiatives were dependent upon implementation strategies. The purpose of the X:IT school-based intervention by Bast et al. (2017) was to prevent adolescent smoking. The cluster-randomized 
controlled trial revealed that the odds for adolescent smoking in intervention school were less than control schools (aORs 0.45-0.81; 95\% CI) (Bast et al., 2017). Schools with higher levels of implementation success were associated with strong administrative leadership, alignment with the mission statement, and an accepting school culture (Bast et al., 2017). According to Bast et al. (2017), interventions that align with a school's mission statement are easier to implement. Bast et al. (2017) also recommended engagement from school leadership and faculty, as well as open, effective communication. Overall, the study supported the need for properly implemented, school-based interventions designed to prevent adolescent smoking.

The need for vaping-specific education in schools is further supported in a study conducted by Anand et al. (2015). The purpose of the cross-sectional, nonexperimental study was to explore the "prevalence, attitudes, and risk factors" associated with e-cigarettes in high school students (Anand et al., 2015, p. 46). Similar to other studies conducted, most respondents reported that vaping was a safe alternative to traditional cigarette smoking (Anand et al., 2015). A total of $61 \%$ of students stated that they were unaware that e-cigarettes contain nicotine (Anand et al., 2015). Unfortunately, 89.7\% of students reported never receiving any information during health education class on the dangers of e-cigarettes (Anand et al., 2015). Recommendations from this study included identification of e-cigarette users and involvement from school faculty and care providers (Anand et al., 2015). Identifying students at risk for ecigarette use is necessary for targeted interventions for prevention and cessation of adolescent vaping (Anand et al., 2015).

Kristjansson, Mann, Smith, and Sigfusdottir (2017) and Owusu et al. (2019) conducted cross-sectional research projects in middle school students within West Virginia and Tennessee, respectively. The purpose of the study by Kristjansson et al. (2017) was to determine the social 
profiles of West Virginia adolescents who use electronic cigarettes due to the alarming rate of adolescent vaping. Middle school students in 15 public West Virginia schools participated in the survey which evaluated the following: smoking status, familial support, academic performance, peer influences, and leisure time (Kristjansson et al., 2017). Non-smoking students reported stronger familial support compared to e-cigarettes users (aOR 1.033, 95\% CI 1.14-1.55) (Kristjansson et al., 2017). Parental supervision was higher among the non-smokers than the students who used vapes (aOR 0.95, p 0.456) (Kristjansson et al., 2017).

Owusu et al. (2019) examined the use of alternative tobacco products among adolescents in Central Appalachia. Middle school students participated in a school-based tobacco survey answering questions regarding use of tobacco products, peer pressure, and risks of tobacco use (Owusu et al., 2019). According to Owusu et al. (2019), adolescents who believe that alternative tobacco products increase popularity are more likely to use e-cigarettes (aOR 6.93, 95\% CI 2.7517.44). Additionally, adolescents who believe that all tobacco products are dangerous were nearly $70 \%$ less likely to use an alternative tobacco product compared to students who did not report that all tobacco products are dangerous (aOR 0.31, 95\% CI 0.11-0.88) (Owusu et al., 2019). Findings from both studies concluded that the use of alternative tobacco products, specifically electronic cigarettes, are appealing to the adolescent population and intervention is necessary.

A pilot study conducted by Pentz et al. (2019) encouraged engaging adolescents with videogames for the prevention of tobacco use. Videogames are more appealing and timeefficient than other educational programs (Pentz et al., 2019). The purpose of the study was to determine the effects of an interactive videogame on adolescents' knowledge, beliefs, and likelihood to engage in future vaping (Pentz et al., 2019). Results from the statistical analysis 
revealed that gameplay changed adolescents' knowledge and perceptions as well as negative health beliefs regarding tobacco use at the evaluation ( $\mathrm{p}<0.001, \mathrm{p}<0.05$, respectively) (Pentz et al., 2019). According to Pentz et al. (2019), further research on the use of adolescent videogames should be conducted. The interactive video game for tobacco prevention guided the life-size board game that was implemented in this quality improvement project.

A systematic review performed by Duncan, Pearson, and Maddison (2018) included 16 studies administered in a variety of settings, including healthcare facilities, schools, homes, and family or peer-lead settings. The focus of this review was to determine successful interventions to prevent smoking initiation in participants under the age of 18 years (Duncan et al., 2018). Criteria for studies included in the systematic review were: children and adolescents aged 7 to 18 years; application of a smoking prevention strategy; experimental study design; and a postintervention outcome (Duncan et al., 2018). While school-based programs, healthcare settings, and community events were successful in reducing adolescent smoking, there were challenging limitations for effective outcomes (Duncan et al., 2018).

Healthcare providers are viewed as a credible source of information and their medical opinions are often valued by patients (Duncan et al., 2018). While primary healthcare settings, such as well-child visits, are optimal for discussing smoking prevention, time is often a limiting factor (Duncan et al., 2018). Community settings are ideal because there is an attentive audience and an established time frame; however, staff may not be educated or trained to deliver smokingprevention education (Duncan et al., 2018). Duncan et al. (2018) recommended utilizing positive interpersonal communications for prevention of smoking. The information obtained from this systematic review was applicable to vaping prevention and intervention to decrease the number of adolescents who currently use e-cigarettes. 
Case et al. (2017) sought to determine the association between sensation-seeking adolescents and e-cigarette use through the Texas Adolescent Tobacco and Marketing Surveillance System (TATAMS). The three year, longitudinal study measured participants in sixth, eighth, and tenth grades baseline and evaluated the use of tobacco products, personal factors, and exposure to marketing of tobacco products (Case et al., 2017). According to Case et al. (2017), adolescents who exhibited higher sensation-seeking scores had greater odds of susceptibility to e-cigarettes (aOR $1.25 ; 95 \% \mathrm{CI}$ ) and higher odds of ever using an e-cigarette (aOR $1.24 ; 95 \%$ CI). This study supported the need for early intervention to prevent initiation of e-cigarette use in adolescents (Case et al., 2017). The recommendation for future studies was communication to sensation-seeking adolescents to discourage and prevent the initiation of vaping (Case et al., 2017).

Westling, Rusby, Crowley, and Light's (2016) study to examine the use of e-cigarettes over time revealed that adolescent vaping is highly associated with substance abuse. Online survey responses were obtained from 1,130 eighth grade students and continued every 3 months until the students began ninth grade (Westling et al., 2016). A total of 1,091 students completed the survey at the beginning of their freshman year of high school (Westling et al., 2016). According to Westling et al. (2016), 27.7\% of eighth grade students followed by $31.4 \%$ of ninth grade students reported lifetime use of an e-cigarette. Sixteen percent of eighth grade students who reported never engaging in vaping had experimented with e-cigarettes by spring of ninth grade (Westling et al., 2016). Eighth grade use of e-cigarettes had significant association with lifetime use of other substances, particularly marijuana (phi 0.63) (Westling et al., 2016). Westling et al. (2016) recognized that adolescents typically engage in vaping prior to initiating traditional cigarette smoking or using other substances. 
Further research on the influences of adolescent vaping was conducted by Pentz et al. (2015). Examples of influences include: demographics, social, and executive function deficits (Pentz et al., 2015). This cross-sectional study revealed that students who qualify for free school lunch; parental ownership of e-cigarettes; and executive functioning deficits were at greater risk for adolescent vaping (aOR 1.96, 95\% CI 0.92-4.15; aOR 2.29, 95\% CI 1.01-5.15; aOR 4.99 95\% CI 1.80-13.86, respectively) (Pentz et al., 2015). Predictors for adolescent e-cigarette use included parental ownership of e-cigarette and peers who vape (aOR 3.21, 95\% CI 1.66-6.20; aOR 3.48, 95\% CI 1.27-9.54, respectively) (Pentz et al., 2015). Pentz et al. (2015) recommended educational programs that emphasize executive functioning skills such as goal setting and planned decision-making.

According to Giovacchini et al. (2017), e-cigarette use increases with advancing age. Data was obtained from the North Carolina Youth Risk Behavior Survey (NCYRBS) which is a school-based survey design (Giovacchini et al., 2017). Approximately $19 \%$ of ninth grade students reported lifetime use of e-cigarettes compared to nearly $33 \%$ of twelfth grade students $(p<0.001)$ (Giovacchini et al., 2017). Lifetime use of e-cigarettes was significantly higher than lifetime use of traditional cigarettes, marijuana, cocaine, or other inhalants (Giovacchini et al., 2017). Only $3 \%$ of adolescent e-cigarette users perceived the substances as having "great risk," compared to nearly $17 \%$ of non-vape users (Giovacchini et al., 2017). Giovacchini et al. (2017) recommended educating adolescents on the dangers of e-cigarette use prior to beginning high school. Healthcare providers should be aware of the growing adolescent vaping epidemic and work to address the issue (Giovacchini et al., 2017).

\section{Synthesis of the Literature}

The studies included in this comprehensive literature synthesis supported the need for 
education directed at the middle school population. Two of the analyzed studies, both of which were randomized control trials, discussed the correlation between adolescent e-cigarette use and the need for educational intervention (Bast et al., 2017; Conner et al., 2019). School-based interventions were deemed successful in the research, especially those which align closely with the school's mission statement (Bast et al., 2017). Evidence from the systematic review concluded that education directed at tobacco prevention is most successful in the community setting due to the willingness and acceptance to participate (Duncan et al., 2018). The recommendation of the systematic review was interpersonal communication in order to prevent tobacco use among adolescents (Duncan et al., 2018).

The remaining nine articles were cross-sectional or longitudinal studies and further supported the need for adolescent education regarding tobacco prevention. The need for prevention strategies aimed at new tobacco products, specifically electronic cigarettes, were recommended by most studies (Fulton et al., 2018; Kowitt et al., 2019; Pentz et al., 2015). Three studies identified social profiles common among adolescent e-cigarettes users which include the following characteristics: low parental supervision, belief that e-cigarettes increase popularity, free school lunch, parental smoking or e-cigarette use, and peer smoking or e-cigarette use (Kristjansson et al., 2017; Owusu et al., 2019; Pentz et al., 2015). Lack of education was commonly reported among subjects. For example, students reported lack of e-cigarette education in health education classes and unawareness that vaping devices contain nicotine (Anand et al., 2015; Fulton et al., 2018).

Middle school students are vulnerable to initiating e-cigarette use, which can lead to future cigarette smoking, alcohol, and substance use. Adolescent education was recommended by nearly all the studies synthesized. Most researchers recognized the limitations of 
generalizability due to limited population size, indicating a need for additional educational interventions to be implemented. According to the USPSTF (2019), education by primary care clinicians is preferred to reduce the use of tobacco among adolescents. Additional studies directed at adolescent vaping are needed to determine additional evidence-based interventions to combat teen vaping.

\section{Theoretical Framework}

Two theories were utilized to guide the quality improvement project. The first theory, Kotter's 8-Step Change Model, involves overlapping steps, beginning with creating a climate for change (Weber \& Weber, 2019). The framework continued to guide this project through engaging and enabling the organization, followed by implementing and sustaining change (Weber \& Weber, 2019). The primary assumption of Kotter's 8-Step Change Model is that the organization is accepting of change (Barlow, 2015). According to Clarizen (2015), the three building blocks of this framework are teamwork, transparency, and communication. The 8 steps of Kotter's Change Model include: create a sense of urgency, build a guiding coalition, create a strategic vision with initiatives, enlist a volunteer army, remove barriers, sustain acceleration, and institute change (Kotter International, 2019).

The theory of planned behavior was also used to guide the project. According to the theory of planned behavior, behavior is a combination of intentions and perceptions of control (Ajzen, 2019b). Intention is the person's readiness to engage in a certain behavior (Ajzen, 2019b). Actual behavioral control describes the resources the person possesses, which controls their behavior (Ajzen, 2019b). When behavioral control is strong, favorable intentions produce the specific behavior (Ajzen, 2019b). This theory posits that there are three concepts guiding 
human behavior including behavioral beliefs, normative beliefs, and control beliefs (Ajzen, 2019a).

\section{Project}

\section{Description and Design of Evidence-Based Project/Intervention Plan}

This quality improvement project worked to answer the following question: Does an educational program focused on the dangers of vaping, presented by a school-based nurse practitioner, affect vaping knowledge and attitudes in middle school students? A quality improvement project is an interdisciplinary effort to change a problem within the healthcare system (Silver et al., 2016). Collaboration between the project leader, middle school principal, and health education teacher was necessary for the implementation of the quality improvement project. To determine change over time, a pre-test/post-test design was used.

The quality improvement project was conducted on January 14, 2020 at 8 a.m. in school's band room. Total enrollment at the middle school is 248 students, which differs from the actual sample size due to attendance on the day of implementation. Each grade level entered the band room separately. The session began with the eighth grade class, followed by the seventh grade, then sixth grade class. Participation in the educational session and interactive game, as well as completion and submission of the pre- and post-tests, were voluntary.

Upon entrance into the school's band room, each student received a packet containing a demographic survey on orange paper, a pre-educational questionnaire on green paper, and a posteducational questionnaire on red paper. The purpose of the various paper colors was to deidentify the participants. The questionnaires were randomly numbered beginning with 001 and it was not possible to associate the random numbers with the students. The questionnaires were designed for a 5 th grade literacy level. By completing the questionnaires and returning them to 
the project leader at the end of the session, students provided assent for participation. The demographic survey and pre- and post-tests are disclosed in Appendices A, B, and C, respectively.

Once seated in the band room, students were asked to anonymously complete the 3 -item demographic survey printed on the orange paper and the 8-item pre-test printed on the green paper. Students were given approximately 10 minutes to complete the two questionnaires. Then, students were asked to store their questionnaire packets within their bookbags or personal items during the presentation and game. Next, the school-based FNP presented a 15-minute educational session on the dangers of vaping. Educational content materials included components from Tar Wars, a youth tobacco prevention program developed in 1988 (American Academy of Family Physicians [AAFP], 2019). The program guidelines are consistent with recommendations from the CDC and there have been statistical improvements in students' knowledge and attitudes toward tobacco use on evaluations (AAFP, 2019). A detailed educational presentation outline is provided in Appendix D.

After the brief educational presentation, an interactive game allowed students to put their knowledge into practice. The nurse practitioner created a life-size board game which was guided by an evidence-based pilot study conducted by Pentz et al. (2019). The pilot study utilized a video game, smokeSCREEN, to increase middle school students' knowledge about tobacco use (Pentz et al., 2019). Each student's virtual character navigated through the game by answering tobacco-related scenario questions (Pentz et al., 2019). Results found that students' risk perceptions and negative health beliefs toward tobacco increased following the videogame (Pentz et al., 2019). Following promising results from the pilot study conducted by Pentz et al. 
(2019), Hieftje, Fernandes, and Fiellin (2019) conducted a comprehensive research study to analyze tobacco prevention following videogame intervention.

Hieftje et al. (2019) implemented smokeSCREEN in school or afterschool programs throughout California, Rhode Island, Massachusetts, and Arizona. The final sample size included 560 participants between the ages of 10 to 14 years; however, inclusion criteria was 10 to 16 years (Hieftje et al., 2019). The implementation of smokeSCREEN was successful in changing the knowledge and beliefs of adolescents regarding tobacco use. Following videogame play, there was an $8.2 \%$ increase $(\mathrm{p}$-value $<.0001)$ in the amount of students who believed that e-cigarettes were dangerous (Hieftje et al., 2019). The study recommended further research on school-based interventions, which was the purpose of this quality improvement project (Hieftje et al., 2019).

Due to the rural location, limited funding, and minimal resources, providing students with electronic devices to play a videogame was unrealistic. The FNP implemented a life-sized board game following the educational presentation. Eight volunteers were chosen to serve as team leaders as well as the life-size piece for the board game. Students were then randomly placed into teams of approximately nine students. Each team was asked a scenario-style question, which required application of their vaping knowledge and perceptions. The team leaders received input from their group members before answering the question. If the team provided a healthy response to the question, the team leader rolled the large die and advanced on the game board.

The life-size game took approximately 25 minutes to complete and provided students with an entertaining, interactive application of their knowledge. Students were required to communicate with their peers and recall information discussed during the presentation. Unlike the studies conducted by Pentz et al. (2019) and Hieftje et al. (2019), this activity only involved 
situations pertaining to electronic cigarettes. The educational session and interactive nature of the game implemented by the FNP grasped the attention of the middle school students, leading to a change in knowledge and attitudes. The quality improvement project was implemented in the following order: demographic survey/pre-test, educational presentation, interactive game, posttest. Each session was approximately 1 hour per class.

The health education teacher and school-based FNP were present and involved in the implementation of the project. Following the completion of the life-size board game, students were given 10 minutes to voluntarily complete the 8 question post-test on red paper. Students were given the option to return the packet for data analysis by placing it into a locked drop-box or into a locked shred box, both located at the exit of the band room. The locked drop-box was orange and the locked shred box was black. Students were not allowed to exit the cafeteria with the packets to prevent other students from having access to questions prior to the educational session. Pre- and post-tests will remain locked in the project leader's file for a 5-year period, then all data will be shredded.

\section{Instruments.}

The pre- and post-test questions were modeled from two studies. The first study was a cross-sectional, nonexperimental design conducted by Anand et al. (2015). The purpose of the Anand et al. (2005) study was to examine prevalence and risk factors of e-cigarette use in high school students (Anand et al., 2015). Questions utilized by the authors were modified after "Monitoring the Future," an ongoing research and reporting project of America's youth (Anand et al., 2015; University of Michigan, 2019). The second study was a cross-sectional study of nurses' knowledge, attitudes, subjective norms, and practices regarding e-cigarettes (Mbe, 
Ayodele, \& Doss, 2017). The study concluded a lack of knowledge among nurses regarding ecigarette use as well as a variety of beliefs regarding vaping safety (Mbe et al., 2017).

Due to the limited number of valid, reliable vaping questionnaires directed at the middle school population, the project leader created pre- and post-tests guided by the questionnaires utilized by Anand et al. (2015) and Mbe et al. (2017). Questions applicable to the project's goals and objectives were required to accurately evaluate the change in adolescents' knowledge and attitudes. The questions were also created to ensure literacy and comprehension within the target population. Authors of both studies were contacted and informed of the quality improvement project (V. Anand, personal communication, August 26, 2019; O. Ayodele, personal communication, October 28, 2019).

\section{Applicability of Theoretical Framework}

Kotter's 8-Step Change Model guided the changes occurring at the system level.

Step One is to create a sense of urgency within the organization (Kotter International, 2019). A sense of urgency existed at the middle school due to the overwhelming number of vaping devices that were confiscated throughout the previous academic year. Numerous middle school students were disciplined for actively engaging in the use of tobacco on school property, particularly vapes. The next step of Kotter's Change Model is to build a guiding coalition to achieve team cohesion and confront the issue of adolescent vaping (Clarizen, 2015; Kotter International, 2019; Weber \& Weber, 2019). The guiding coalition of this project was led by the school-based FNP and included the principal, health education teacher, and school nurse.

Step Three is the creation of a strategic vision with initiatives (Kotter International, 2019). This step incorporated the goals of the project which were to change the beliefs and attitudes among middle school students regarding vaping. The first vision of this project was to 
decrease the number of students who believe vaping is safer than traditional cigarette smoking. The second vision was for students to change their attitudes by recognizing e-cigarettes as a health hazard. The initiative of a brief educational presentation and interactive game achieved the visions of the project.

Enlisting a volunteer army or communicating the vision is the next step of the theoretical framework (Clarizen, 2015; Kotter International, 2019). This group was comprised of similar individuals from the guiding coalition group listed in Step Two; however, additional community involvement at this point in the project was desired. Achievement of this step will continue through implementation of this project at various school-based sites throughout two counties in rural West Virginia. Step Five is the removal of barriers to enable action (Kotter International, 2019). The most anticipated barrier for this project was reserved time for the educational session and activity. The barrier was eliminated with effective communication and planning between the project leader and school administration.

Step Six is to generate short-term wins, which are vital to sustain momentum and achieve long-term goals (Clarizen, 2015; Kotter International, 2019). The short-term wins of this project are to decrease the prevalence of vaping; change knowledge and attitudes regarding vaping; and prevent initiation of vaping. Achievement of the short-term goals will demonstrate decreased risks among students at the middle school. The short-term wins of this project were measured by data analysis; however, short-term wins will continue to be measured throughout the academic year. Comparison of the number of vaping devices confiscated following the implementation of this project will be compared to previous academic years.

The next step is to sustain acceleration to improve systems and policies (Kotter International, 2019). Sustaining acceleration is an ongoing step following the implementation of 
the project. Following achievement of the short-term goals, stakeholders are likely to be optimistic and engaged in the next challenge, which is vital for sustainability of the project. Working toward changing statewide health education curriculum to include vaping education and vaping policies have begun and will continue through dissemination of knowledge. Step Eight of Kotter's 8-Step Change Model is to institute change (Kotter International, 2019). This step is essential for the maintenance and sustainability of the project. Ideally, educational sessions informing students on the dangers of vaping will be continued indefinitely in middle schools across the state as a result of policy change. A goal of this project is to lead West Virginia schools to the development of a specific vaping policy, preventing the presence of any type of electronic cigarette on school property.

The theory of planned behavior was applied to the individual behaviors of the adolescents. The first concept, behavioral belief, describes the belief about potential consequences of the behavior (Ajzen, 2019a). The goal of the quality improvement project was to change the behavioral belief that vaping is safer than traditional cigarette smoking. The second concept of normative beliefs is the belief of what others view as normal (Ajzen, 2019a). These beliefs lead to a subjective norm or social pressure (Ajzen, 2019a). This concept is an issue with many health risks in the adolescent population because peer pressure greatly impacts the decisions of adolescents.

The final concept of this theory, control beliefs, is how an individual perceives factors that could facilitate or impede the behavior (Ajzen, 2019a). The educational presentation and interactive game informed the middle school students that help is available for those who desire vaping or smoking cessation. The FNP also discussed how the stakeholders will support students who desire to quit using tobacco. The education implemented during the quality 
improvement project encouraged students to change their behavioral, normative, and control beliefs. By changing their beliefs on the dangers of vaping, the middle school students are more likely to refuse or stop using e-cigarettes. The change in attitude was evaluated on the students' pre- and post-tests.

\section{Feasibility Analysis}

The following sections provide details regarding the need and justification for this quality improvement project. The necessity and feasibility of this project was supported through a detailed needs assessment; strengths, weaknesses, opportunities, and threats (SWOT) analysis; and market analysis. The overall health benefit of the project exceeded the weaknesses.

\section{Needs assessment.}

The key stakeholders of the project included the students, parents, teachers, school nurse, and school-based nurse practitioner in addition to the school's principal and health education teacher. Communication and planning between the stakeholders, specifically the principal, were essential for the project's success. Content for the quality improvement project was derived from multiple sites including Healthy People 2020, Centers for Disease Control and Prevention, and the U.S. Preventative Services Task Force. Education for students was obtained from Tar Wars, a program directed at preventing tobacco use among youth (AAFP, 2019).

Responses remained confidential and anonymous, preventing extraneous privacy concerns. The project was welcomed due to the notable prevalence of vaping among students and the faculty's desire for student-provider interaction. A slight interference in the faculty's workflow occurred due to the need for dedicated educational session time. Faculty members were permitted to attend and observe the educational session, which many vocalized as 
informative and interesting. Technical issues were not of concern because the questionnaires were not electronic.

\section{Market analysis.}

The project was less costly than other educational interventions which increased the ease of implementation and support from the site. The project did not require administrative, marketing, hospitality, or traveling expenses. The total cost for educational materials, incentives, and project supplies was approximately 250 dollars. Approximately 220 dollars were utilized for the project gameboard and incentives, including supplies for hands-on activities, treats for student participation, and rewards for winning the interactive game. The remaining cost was associated with the project supplies such as ink and paper for the questionnaires. The actual project costs were lower than the projected project budget. While this project was both economical and practical, the potential long-term outcomes for adolescent health are tremendous. A detailed budget plan is listed in Appendix E.

\section{Strategic analysis.}

The strengths and opportunities of this project were numerous. Foremost, this project has the potential to reduce morbidity and mortality related to tobacco use. It addressed the current health issue of adolescent vaping at the local middle school and worked to achieve a Healthy People 2020 goal. The project was cost-effective and required minimal resources. Most stakeholders were employees at the project site and were eager about changing the students' attitudes and beliefs on vaping. The opportunity for the FNP to educate the students on the dangers of vaping was invaluable. The project has an opportunity for future health education curriculum changes at the county and state levels. Adolescents will likely disseminate the information learned during the educational sessions to peers and relatives, which will also assist 
in achieving the Healthy People 2020 goal to "reduce illness, disability, and death related to tobacco use and secondhand smoke exposure" (USPSTF, 2019).

There were few potential weaknesses and threats for the proposed project. Weaknesses included interrupted classroom time; however, this was managed with communication and planning between the FNP, principal, and health education teacher. The implementation site was in rural West Virginia, which resulted in a homogeneous sample. With effective communication, planning, and interprofessional collaboration, the controllable weaknesses of the proposed project were minimized.

\section{Sustainability.}

The educational component and interactive game of the quality improvement project are sustainable and will likely continue in the following academic years. Other schools in the surrounding areas are likely to implement the content to educate their students on the dangers of vaping. Vaping has gained popularity and is now a national health concern being addressed by the President of the United States; therefore, current and future education will be necessary. The quality improvement project also has the potential to be replicated in the future in order to obtain more data.

\section{Congruence of organization's strategic plan to project.}

The mission of Nicholas County Schools is to educate students for success in life (Nicholas County Schools, 2019). The project aligned with Nicholas County Schools' mission statement because it provided education to students which will help them reach their full potential and live successful, healthy lives. Regulations promoted the project because adolescent vaping and tobacco use on school property are illegal and can result in criminal penalties. 


\section{Evidence of key site support.}

The middle school principal fully supported the project, as evidenced by Appendix F. Due to the overwhelming number of adolescents who have been disciplined for vaping, the principal encouraged the educational intervention. Additional school staff such as the school nurse, health education teacher, and secretary also supported the proposed quality improvement project. The principal altered scheduled class time on the day of implementation.

\section{Measurable Project Objectives}

- Goal: Change the attitudes regarding the severity of vaping among middle school students.

O Objective: Compare responses on pre- and post-tests to determine if the educational session implemented by the nurse practitioner changed the students' attitudes.

○ Measurable Outcome: Demonstrate a $10 \%$ increase in the number of middle school students who report e-cigarettes as a health problem in America by the post-test.

○ Statistical Analysis: McNemar chi-square

- Goal: Increase knowledge of middle school students regarding the dangers of vaping.

○ Objective: Compare responses on pre- and post-tests to determine if the educational session implemented by the nurse practitioner increased the students' knowledge.

- Measurable Outcome: Demonstrate a 15\% decrease in the number of middle school students who report that vaping is safer than traditional cigarette smoking by the posttest.

- Statistical Analysis: McNemar chi-square

Data from returned demographic surveys and pre- and post-tests was manually entered into Statistical Package for the Social Sciences (SPSS) software. A descriptive analysis was utilized to explain the demographic data obtained from participants. The method of statistical 
analysis used for questions 1 and 3 on the pre- and post-tests was the Wilcoxon signed-rank test, which compares two answers from the same participants (Laerd Statistics, 2018b). The remaining six variables were statistically analyzed utilizing the McNemar chi-square test, which determines if there is a difference between dichotomous dependent variables (Laerd Statistics, 2018a).

\section{Results}

Total enrollment at the middle school during the time of implementation was 248 students. On the day of implementation, 212 students were present. All students chose to attend the vaping session implemented by the school-based nurse practitioner. The sample size for data analysis was 174 participants, which was an $82 \%$ response rate. Students' ages ranged from 11 years to 15 years, with a mean of 12.64 years and included grades six through eight. The majority of participants were females, indicated by $48.9 \%$ of students. Male students encompassed $47.7 \%$ of participants, while the remaining $3.4 \%$ of students chose not to disclose their gender. Results were considered statistically significant if p-value was <.05.

The measurable outcomes of this quality improvement project were analyzed utilizing the McNemar chi-square test conducted through the SPSS application. The purpose of the McNemar chi-square test is to determine the difference between a repeated dichotomous variable (Laerd Statistics, 2018a). The first goal of this quality improvement project was to change attitudes regarding the severity of vaping among middle school students. The measurable outcome, demonstrate a $10 \%$ increase in the number of middle school students who report ecigarettes as a health problem in America by the post-test, was not achieved. According to the pre-survey, $87.6 \%$ percent of students viewed vaping as a health problem in the United States. 
On the post-survey, $89.1 \%$ of students indicated that vaping is a national health problem, increasing by $1.5 \%$. This result was determined statistically insignificant with a p-value of .815 .

The second measured outcome, demonstrate a $15 \%$ decrease in the number of middle school students who believe that vaping is safer than traditional cigarette smoking by the posttest, was successful. Prior to the educational intervention, $25.9 \%$ of participants reported electronic cigarettes as a safe alternative to cigarette smoking. Post-test responses revealed that $10.1 \%$ of students view vaping as a safe alternative to cigarette smoking, The $15.8 \%$ decrease in adolescents who believe vaping is a safer than smoking was statistically significant with a pvalue of .000 .

Two unintended variables were also found to be statistically significant during data analysis. Responses from the pre- and post-test question "How much do you know about electronic cigarettes/e-cigarettes/vapes?" were analyzed by the Wilcoxon signed-rank test. The Wilcoxon signed-rank test compares changes in two responses from the same participant over time (Laerd Statistics, 2018b). This statistical analysis was applied due to ordinal variables (i.e., Likert-style responses) (Laerd Statistics, 2018b). Initially, 21.8\% of students reported knowing "a lot" about vaping. The post-test responses revealed that $49.7 \%$ of students reported knowing “a lot" about vaping, indicating 27.9\% increase in students' knowledge. This value was statistically significant with a p-value of .000 .

The second unintended variable that was statistically significant was "How did you learn about the electronic cigarettes/e-cigarettes/vapes?" This variable was also analyzed with the Wilcoxon-signed rank test because more than one option was allowed to be chosen by the respondents. Approximately $56 \%$ of students reported the media as their source of information on vaping on pre-surveys. According to post-survey responses, $62.3 \%$ of students reported 
media as their source of vaping information. The $6.2 \%$ increase in media as the primary source of vaping information for adolescents was statistically significant with a p-value of .012 . The remaining five variables were not statistically significant. Refer to Appendices $\mathrm{G}$ and $\mathrm{H}$ for continued results.

\section{Discussion}

Overall, this quality improvement project was deemed successful. Statistical results demonstrated a $15.8 \%$ decrease in adolescents who believe vaping is safer than smoking following the educational intervention by the school-based nurse practitioner. Data also revealed a $27.9 \%$ increase in students' knowledge regarding vaping after the educational session and game. The project was feasible, practical, and welcomed by school faculty and staff.

\section{Limitations}

The project was implemented in the month of January, which is a common time for illnesses. On the day of implementation, only $85 \%$ of students were present which negatively impacted the sample size. Due to staffing conflicts, the school nurse was unable to be involved in the implementation of this project. Involvement from the school nurse would be beneficial in the future and assist with sustainability and daily application of the knowledge obtained. The school does not have a gymnasium due to pending construction; therefore, the session took place in the school's band room.

While all students chose to attend the educational presentation and interactive game, only 174 surveys were submitted to the project leader for inclusion in the quality improvement project. It is likely that students were concerned regarding anonymity due to numbering of survey packets and possible grading of pre- and post-test responses. This resulted in $18 \%$ of packets being placed in the shred box. 
Responses from the question "How did you learn about the electronic cigarettes/ecigarettes/vapes?" were statistically significant with a $6.2 \%$ increase from pre-test to post-test. However, it is unclear why this increase was noted. The assumption is that students referred to the school-based nurse practitioner's presentation as a form of media, prompting participants to select "media" as their source of vaping education.

\section{Recommendations}

The project was implemented between the hours of 8 a.m. and 11 a.m. to avoid conflict with lunch schedules, which is recommended for future implementation. The session began with eighth grade, continued with seventh grade, and concluded with sixth grade. This sequence was most practical due to the scheduling of lunches; however, scheduling is modifiable based on individual schools' preferences. Avoidance of core class interruptions is also recommended for future implementation sites. Involvement and support from the school principal and health education teacher were vital for the success of this project and is necessary for success at other sites.

Modification of the responses for the question "How did you learn about the electronic cigarettes/e-cigarettes/vapes?" is recommended. Pre-survey response options should include "I have not learned about e-cigarettes." This potential response would allow the project leader to highlight the deficit of vaping education throughout our counties, state, or nation. Responses on the post-survey should include an option to select the vaping presentation. This would help eliminate confusion and provide clearer results during data analysis.

In other settings, administration may not be as flexible with the time requirement; therefore, decreased time for the educational session and game may be necessary. A future recommendation to promote completion of pre- and post-surveys is an incentive, such as a gift 
card or small reward. Also, eliminating the random numbering of survey packets is recommended to provide reassurance of anonymity. Implementation of the project within the school's gymnasium would be ideal for future sites. This would allow for a larger life-size game board as well as more space for students' teams. The project should be continued in the upcoming academic years due to the potential to greatly reduce morbidity and mortality among youth.

\section{Attainment of DNP Essentials}

\section{Essential I}

Essential I: Scientific Underpinnings for Practice provides FNPs with the ability to translate knowledge into practice for patient benefit (American Association of Colleges of Nursing [AACN], 2006). Upon discovery of alarming statistics from a detailed literature search, the project allowed the school-based nurse practitioner to utilize extensive medical knowledge to implement a program directed at educating adolescents on the dangers of vaping. The use of two, scientific-based theories were utilized to guide the design and implementation of this project. The project also has potential to greatly benefit adolescent health throughout West Virginia.

\section{Essential II}

Essential II: Organizational and Systems Leadership for Quality Improvement and Systems Thinking encourages focusing on the needs of a target population or community (AACN, 2006). The project coincided with this Essential by directing an educational intervention to a middle school population. Essential II also emphasizes organizational and systems leadership (AACN, 2006). The school-based FNP was viewed as a leader and content expert by school faculty and students. 


\section{Essential III}

Essential III: Clinical Scholarship and Analytical Methods for Evidence-Based Practice promotes translating research into practice as well as disseminating new knowledge (AACN, 2006). Translation of research into practice was achieved by creating an interactive game, guided by an evidence-based tobacco education program, to address the needs of a specific target population. The project leader will disseminate the knowledge obtained through a variety of methods. This project was presented at the West Virginia Nurses Association Policy Summit in February 2020 in the form of an educational poster. The project leader is also presenting this project at the inaugural West Virginia School of Osteopathic Medicine Pediatric Primary Care Poster Symposium, which will occur in 2020. Additional dissemination of the obtained knowledge is planned by seeking inclusion of standardized vaping education and vapingspecific policies into statewide curricula.

\section{Essential IV}

Essential IV: Information Systems/Technology and Patient Care Technology for the Improvement and Transformation of Health Care requires the use of information systems or technology to evaluate the outcomes of care (AACN, 2006). Also, application of budgeting tools and management of information are components of this Essential (AACN, 2006). The project utilized technology to analyze data and conduct statistical testing. All data was manually entered into the SPSS application, followed by electronic statistically analyses. A detailed budget was also created for the project.

\section{Essential V}

Essential V: Health Care Policy for Advocacy in Health Care promotes involvement in designing, influencing, and implementing health care policies (AACN, 2006). This Essential 
aligns closely with a long-term goal of the project, which is statewide health education curriculum change and specific vaping policies. The pilot program at the project site has focused on the immediate policies at the middle school and advocacy within the local community. To change health education curriculum and policies for West Virginia middle schools, the schoolbased nurse practitioner will continue to be engaged with the state legislature and advocate for a program directed at improving adolescent health.

\section{Essential VI}

Essential VI: Interprofessional Collaboration for Improving Patient and Population Health Outcomes requires effective team leadership from the doctorally-prepared nurse practitioner in addition to interprofessional communication (AACN, 2006). Essential VI was portrayed throughout the project through communication between the project leader, school principal, health education teacher, and other faculty members. Effective communication and interprofessional collaboration was essential for the successful implementation of the project. The school-based nurse practitioner continues to lead the interprofessional team dedicated to the health of the school's students.

\section{Essential VII}

Essential VII: Clinical Prevention and Population Health for Improving the Nation's Health is vital to improve the health of United States' citizens (AACN, 2006). Essential VII was the underlying framework for the proposed project. The doctorally-prepared nurse practitioner possesses the knowledge necessary to achieve the goals of health promotion and disease prevention (AACN, 2006). The overarching goal of this project was to educate middle school students on the dangers of vaping, ultimately promoting health and preventing disease. This project also worked to address the Healthy People 2020 goal related to tobacco use. 


\section{Essential VIII}

Essential VIII: Advanced Nursing Practice refers to the competencies that are necessary for advanced practice (AACN, 2006). Doctorate of Nursing Practice (DNP) degrees prepare advanced practice registered nurses for various roles in the healthcare system (AACN, 2006). The project strengthened the leadership and communication skills of the project leader as well promoted credibility throughout the field of primary care and school-based healthcare. The project leader exhibited critical thinking throughout the duration of the project. A professional relationship was developed between the project leader, school administration, and students. 


\section{Bibliography}

Ajzen, I. (2019a). Constructing a theory of planned behavior questionnaire. Retrieved from https://people.umass.edu/aizen/pdf/tpb.measurement.pdf

Ajzen, I. (2019b). Theory of planned behavior diagram. Retrieved from https://people.umass.edu/aizen/tpb.diag.html\#null-link

American Academy of Family Physicians. (2019). Tar wars program guide. Retrieved from https://www.aafp.org/dam/AAFP/documents/patient_care/tobacco/tar_wars/programguide.pdf

American Association of Colleges of Nursing. (2006). The essentials of doctoral education for advanced nursing practice [PDF file]. Retrieved from https://www.aacnnursing.org/Portals/42/Publications/DNPEssentials.pdf

Anand, V., McGinty, K. L., O’Brien, K., Guenthner, G., Hahn, E., Martin, C. A. (2015). Ecigarette use and beliefs among urban public high school students in North Carolina. Journal of Adolescent Health, 57(1), 46-51. doi: 10.1016/j.jadohealth.2015.03.018

Barlow, S. (2015). Reflections on Kotter's eight step model. Retrieved from https://www.thechangegym.com/reflections-on-kotters-eight-step-model/

Bast, L. S., San Publ, C. S., Due, P., Ersboll, A. K., Polyt, C., Damsgaard, M. T., \& Andersen, A. (2017). Association of School Characteristics and Implementation in the X:IT Study - A school-randomized smoking prevention program. Journal of School Health, 87(5), 329337. doi: 10.1111/josh.12500

Case, K. R., Harrell, M. B., Perez, A., Loukas, A., Wilkinson, A. V., Springer, A. E., ... Perry, C. I. (2017). The relationships between sensation seeking and a spectrum of e-cigarette use behaviors: Cross-sectional and longitudinal analyses specific to Texas adolescents. 
Addictive Behaviors, 73, 151-157. doi: 10.1016/j.addbeh.2017.05.007

Centers for Disease Control and Prevention. (2019a). CDC, states update number of cases of lung injury association with use of e-cigarette, or vaping, products. Retrieved from https://www.cdc.gov/media/releases/2019/s-1010-vaping-injury-update.html

Centers for Disease Control and Prevention. (2019b). Map of current cigarette use among youth. Retrieved from https://www.cdc.gov/statesystem/cigaretteuseyouth.html

Centers for Disease Control and Prevention. (2019c). Quick facts on the risks of e-cigarettes for kids, teens, and young adults. Retrieved from https://www.cdc.gov/tobacco/basic_information/e-cigarettes/Quick-Facts-on-the-Risksof-E-cigarettes-for-Kids-Teens-and-Young-Adults.html

Centers for Disease Control and Prevention. (2019d). State highlights. Retrieved from https://nccd.cdc.gov/STATESystem/rdPage.aspx?rdReport=OSH_STATE.Highlights\&rd RequestForwarding=Form

Centers for Disease Control and Prevention. (2020). Outbreak of lung injury associated with ecigarette use, or vaping. Retrieved from https://www.cdc.gov/tobacco/basic_information/e-cigarettes/severe-lung-disease.html

Clarizen. (2015). An overview of Kotter's 8 steps of change management. Retrieved from https://www.clarizen.com/overview-kotters-8-steps-change-management/

Conner, M., Grogan, S., Simms-Ellis, R., Flett, K., Sykes-Muskett, B., Cowap, L. ... Siddiqi, K. (2019). Evidence that an intervention weakens the relationship between adolescent electronic cigarette use and tobacco smoking: A 24-month prospective study. Tobacco Control, 0, 1-7. doi: 10.1136/tobaccocontrol-2018-054905

Consumer Advocates for Smoke Free Alternatives Association. (2019). A historical timeline of 
electronic cigarettes. Retrieved from http://www.casaa.org/historical-timeline-ofelectronic-cigarettes/

Duncan, L. R., Pearson, E. S., \& Maddison, R. (2018). Smoking prevention in children and adolescents: A systematic review of individualized interventions. Patient Education and Counseling, 101(3), 375-388. doi: 10.1016/j.puhe.2018.04.014

Fulton, E., Gokal, K., Griffiths, S., \& Wild, S. (2018). More than half of adolescent e-cigarette users had never smoked a cigarette: Findings from a study of school children in UK. Public Health, 161, 33-35. doi: 10.1016/j.puhe.2018.04.014

Giovacchini, C. X., Pacek, L., McClernon, F. J., \& Que, L. G. (2017). Use and perceived risk of electronic cigarettes among North Carolina middle and high school students. North Carolina Medical Journal, 78(1). doi: 10.18043/ncm.78.1.7

Hieftje, K. D., Fernandes, C. S., \& Fiellin, L. E. (2019). Effectiveness of a web-based tobacco product use prevention videogame intervention on young adolescents' beliefs and knowledge. Substance Abuse, doi: 10.1080/08897077.2019.1691128

Kotter International. (2019). 8-step process. Retrieved from https://www.kotterinc.com/8-stepsprocess-for-leading-change/

Kowitt S. D., Goldstein, A. O., Sutfin, E. L., Osman, A., Meernik, C., Heck, C., \& Ranney, L. M. (2019). Adolescents' first tobacco products: Associations with current multiple tobacco product use. PLOS ONE, 14(5), 1-16. doi: 10.1371/journal.pone.0217244

Kristjansson, A. L., Mann, M. J., Smith, M. L., \& Sigfusdottir, I. D. (2017). Social profile of middle school-aged adolescents who use electronic cigarettes: Implications for primary prevention. Prevention Science, 19(6), 805-812. doi: 10.1007/s11121-017-0825-x 
Laerd Statistics. (2018a). McNemar's test using SPSS statistics. Retrieved from https://statistics.laerd.com/spss-tutorials/mcnemars-test-using-spss-statistics.php

Laerd Statistics. (2018b). Wilcoxon signed-rank test using SPSS statistics. Retrieved from https://statistics.laerd.com/spss-tutorials/wilcoxon-signed-rank-test-using-spssstatistics.php

Lechner, W. V., Murphy, C. M., Colby, S. M., Janssen, T., Rogers, M. L., \& Jackson, K. M. (2018). Cognitive risk factors of electronic and combustible cigarette use in adolescents. Addictive Behaviors, 82, 182-186. doi: 10.1016/j.addbeh.2018.03.006

Mbe, Q., Ayodele, O., \& Doss, D. (2017). Nurses' knowledge, beliefs, attitudes, and practices regarding electronic cigarettes: A cross-sectional study. Retrieved from http://www.tobaccopreventioncessation.com

Milicic, S., DeCicca, P., Pierard, E., \& Leatherdale, S. T. (2018). An evaluation of school-based e-cigarette control policies' impact on the use of vaping products. Tobacco Induced Diseases, 16(35), 2-9. doi: 10.18332/tid/93594

National Institute of Health. (2018). Teens using vaping devices in record numbers. Retrieved from https://www.nih.gov/news-events/news-releases/teens-using-vaping-devices-recordnumbers

Nicholas County Schools. (2019). Nicholas County board of education. Retrieved from http://ncboe.ss8.sharpschool.com/

Office of Disease Prevention and Health Promotion. (2019). Tobacco use. Retrieved from https://www.healthypeople.gov/2020/topics-objectives/topic/tobacco-use

Owusu, D., Mamudu, H. M., Collins, C., Robertson, C., Wang, L., Rafie, B., \& Littleton, M. A. (2019). The usage and associated factors of alternative tobacco products among school- 
going youth in Central Appalachia. Journal for Health Care for the Poor and Underserved, 30(1), 249-264. doi: 10.1353/hpu.2019.0019

Pentz, M. A., Shin, H., Riggs, N., Unger, J. B., Collison, K. L., \& Chou, C. (2015). Parent, peer, and executive function relationships to early adolescent e-cigarette use: A substance use pathway? Addictive Behaviors, 42, 73-78. doi: 10.1016/j.addbeh.2014.10.040

Pentz, M. A., Hieftje, K. D., Pendergrass, T. M., Brito, S. A., Liu, M., Arora, T., ... Fiellin, L. E. (2019). Videogame intervention for tobacco product use prevention in adolescents. Addictive Behaviors, 91, 188-192. doi: 10.1016/j.addbeh.2018.11.016

Silver, S. A., Harel, Z., McQuillan, R., Weizman, A. V., Thomas, A., Chertow, G. M. ... Chan, C. T. (2016). How to begin a quality improvement project. Clinical Journal of American Society of Nephrology, 11(5), 893-900. doi: 10.2215/CJN.11491015

University of Michigan. (2019). Monitoring the Future: Drug use and lifestyles of American Youth (MTF). Retrieved from https://www.src.isr.umich.edu/projects/monitoring-thefuture-drug-use-and-lifestyles-of-american-youth-mtf/

U.S. Preventive Services Task Force. (2019). Draft recommendation statement: Prevention and cessation of tobacco use in children and adolescents: Primary care interventions. Retrieved from https://www.uspreventiveservicestaskforce.org/Page/Document/draftrecommendation-statement/tobacco-and-nicotine-use-prevention-in-children-andadolescents-primary-care-interventions

Walton, S., Peskin, A., Fewer, S. L., Safai, A., Yee, N., \& Brown, V. (2019). Ordinance amending the Health Code to prohibit the sale by tobacco retail establishments of electronic cigarettes that require, but have not received, an order from the Food and Drug Administration (FDA) approving their marketing; and prohibiting the sale and 
distribution to any person in San Francisco of flavored tobacco products and electronic cigarettes that require, but have not received, an FDA order approving their marketing. Retrieved from https://sfgov.legistar.com/View.ashx?M=F\&ID=7111897\&GUID=7C3912E3-BB56420D-896E-6FEA1391287D

Weber, V., \& Weber, M. (2019). Successful change management - Kotter's 8-step change model. Retrieved from https://www.leadershipthoughts.com/kotters-8-step-changemodel/\#kotters8stepchangemodelforleadingchange

Westling, E., Rusby, J. C., Crowley, R., \& Light, J. M. (2016). Electronic cigarette use by youth: Prevalence, correlates, and use trajectories from middle to high school. Journal of Adolescent Health, 60, 660-666. doi: 10.1016/j.jadohealth.2016.12.019 


\section{Appendix A}

\section{Demographic Questionnaire}

1. What is your age?

2. What grade are you in?

3. What is your gender? 


\section{Appendix B}

\section{Pre-Intervention Questionnaire}

Please DO NOT write your name or any information on this paper. Circle your answer.

1. Have you ever heard of electronic cigarettes, e-cigarettes, or vapes?

YES NO

2. How did you learn about the electronic cigarettes/e-cigarettes/vapes? (Choose all that apply)

$\begin{array}{lll}\text { MEDIA } & \text { NEWSPAPER } & \text { ROADSIDE POSTER (BILLBOARD) } \\ \text { FRIEND } & \text { FAMILY } & \text { OTHER }\end{array}$

3. How much do you know about electronic cigarettes/e-cigarettes/vapes?

NOTHING AT ALL A LITTLE A LOT

4. Have you ever used an e-cigarette/vape/JUUL ®?

YES NO NOT SURE

5. Are electronic cigarettes/e-cigarettes/vapes safer to use than regular cigarettes?

YES NO

6. Electronic cigarettes/e-cigarettes/vapes may lead to "regular" cigarette smoking.

YES NO

7. Is vaping a health problem in America?

YES NO

8. Should electronic cigarettes/e-cigarettes/vapes be allowed in schools and public places?

YES NO

Questions modeled from Anand et al. (2015) and Mbe et al. (2017) 


\section{Appendix C \\ Post-Intervention Questionnaire}

Please DO NOT write your name or any information on this paper. Circle your answer.

1. Have you ever heard of electronic cigarettes, e-cigarettes, or vapes?

YES NO

2. How did you learn about the electronic cigarettes/e-cigarettes/vapes? (Choose all that apply)

$\begin{array}{lll}\text { MEDIA } & \text { NEWSPAPER } & \text { ROADSIDE POSTER (BILLBOARD) } \\ \text { FRIEND } & \text { FAMILY } & \text { OTHER }\end{array}$

3. How much do you know about electronic cigarettes/e-cigarettes/vapes?

NOTHING AT ALL A LITTLE A LOT

4. Have you ever used an e-cigarette/vape/JUUL ®?

YES NO

5. Are electronic cigarettes/e-cigarettes/vapes safer to use than regular cigarettes?

YES NO

6. Electronic cigarettes/e-cigarettes/vapes may lead to "regular" cigarette smoking.

YES NO

7. Is vaping a health problem in America?

YES NO

8. Should electronic cigarettes/e-cigarettes/vapes be allowed in schools and public places?

YES NO

Questions modeled from Anand et al. (2015) and Mbe (2017). 


\section{Appendix D}

\section{Content Outline}

\section{A. Activity 8 : Electronic Cigarettes}

- Will discuss how electronic cigarettes are not safe alternative to traditional cigarettes

- Information will provide description of electronic cigarette, toxic ingredients, and brain effects

- Approximately 5 minutes duration

B. Activity 9: What is a JUUL $®$ ?

- Will discuss the dangers associated with JUULs ${ }^{\circledR}$

- Will describe the function of a JUUL®

- Information will explain how JUULs ${ }^{\circledR}$ negatively affect health

- Approximately 5 minutes duration

C. Activity 12: Reasons People Use Tobacco

- Will discuss the reasons that people use tobacco products

- Will discuss the impact of peer pressure and image

- Will educate students on the potential for addiction

- Approximately 5 minutes duration

Activities are derived from the Tar Wars Program Guide 2019-2020 School Year (AAFP, 2019). 
Appendix E

Budget

\begin{tabular}{|c|c|c|c|}
\hline Budget Categories & $\begin{array}{l}\text { Personal } \\
\text { Funds }\end{array}$ & $\begin{array}{l}\text { Organizational } \\
\text { Contributions }\end{array}$ & \\
\hline & \multicolumn{2}{|c|}{ Projected Costs } & Actual Costs \\
\hline ADMINISTRATIVE COSTS & $\$ 0$ & $\$ 0$ & $\$ 0$ \\
\hline \multicolumn{4}{|l|}{ Administrative Justification: N/A } \\
\hline Marketing & $\$ 0$ & $\$ 0$ & $\$ 0$ \\
\hline \multicolumn{4}{|l|}{ Marketing Justification: N/A } \\
\hline $\begin{array}{l}\text { EDUCATIONAL MATERIALS/ } \\
\text { INCENTIVES }\end{array}$ & $\$ 100$ & $\$ 100$ & $\$ 220$ \\
\hline \multicolumn{4}{|c|}{$\begin{array}{l}\text { Educational Materials/Incentives Justification: Supplies for activities, candy } \\
\text { for participation, etc. }\end{array}$} \\
\hline $\begin{array}{l}\text { HOSPITALITY (food, room rentals, } \\
\text { etc.) }\end{array}$ & $\$ 0$ & $\$ 0$ & $\$ 0$ \\
\hline \multicolumn{4}{|l|}{ Hospitality Justification: N/A } \\
\hline $\begin{array}{l}\text { PROJECT SUPPLIES (office } \\
\text { supplies, postage, printing, etc.) }\end{array}$ & $\$ 0$ & $\$ 100$ & $\$ 30$ \\
\hline \multicolumn{4}{|c|}{ Project Supplies Justification: Printing/copying costs for pre- and post-tests } \\
\hline TRAVEL EXPENSES & $\$ 0$ & $\$ 0$ & $\$ 0$ \\
\hline \multicolumn{4}{|l|}{ Travel Expenses Justification: N/A } \\
\hline OTHER & $\$ 180$ & $\$ 0$ & $\$ 180$ \\
\hline \multicolumn{4}{|c|}{ Other Justification: Nurse practitioner expense - donated } \\
\hline TOTALS & $\$ 100$ & $\$ 200$ & $\$ 250$ \\
\hline
\end{tabular}

Appendix F

Site Support Verification 
Site Support Verification

This document is to verify that Holly Fitzwater, West Virginia University Doctorate of Nursing Practice student, has permission to conduct the proposed project regarding the dangers of vaping at Richwood Middle School. The project conducted by the student will receive approval from West Virginia University Institutional Review Board (IRB) before initiation. The project is also being overseen by the student's faculty of record, Dr. Teresa Ritchie, DNP, APRN, FNP-BC. This study is not related to the student's employment with Camden Family Health.

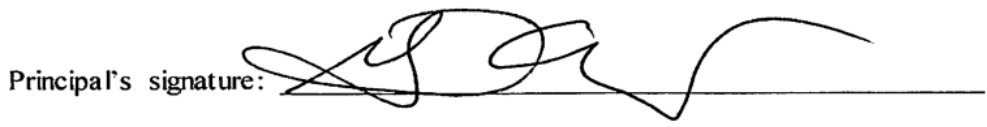

Date: $7 / 10 / 19$ 
Appendix G

Results

Table 1.

Wilcoxon Rank Test Results

\begin{tabular}{|c|c|c|c|c|c|c|}
\hline \multirow[t]{2}{*}{ Variable } & \multirow[t]{2}{*}{ Response } & \multicolumn{2}{|c|}{ Pre-Test } & \multicolumn{2}{|c|}{ Post-Test } & \multirow[t]{2}{*}{ p-value } \\
\hline & & $n$ & Valid Percent & $n$ & Valid Percent & \\
\hline \multirow{3}{*}{$\begin{array}{l}\text { Q3 } \\
\text { How much do you } \\
\text { know about electronic } \\
\text { cigarettes/e- } \\
\text { cigarettes/vapes? }\end{array}$} & Nothing at all & 8 & 4.7 & 4 & 2.4 & \multirow[t]{3}{*}{.000} \\
\hline & A little & 125 & 73.5 & 79 & 47.9 & \\
\hline & A lot & 37 & 21.8 & 82 & 49.7 & \\
\hline \multirow{3}{*}{$\begin{array}{l}\text { Q4 } \\
\text { Have you ever used an } \\
\text { e-cigarette/vape/JUUL } \\
\circledR ?\end{array}$} & No & 116 & 67.1 & 113 & 68.5 & \multirow[t]{3}{*}{.062} \\
\hline & Yes & 47 & 27.2 & 52 & 31.5 & \\
\hline & Not sure & 9 & 5.2 & & & \\
\hline
\end{tabular}


Appendix $\mathrm{H}$

Results

Table 2.

McNemar Chi-Square Test Results

\begin{tabular}{|c|c|c|c|c|c|c|}
\hline \multirow[t]{2}{*}{ Variable } & \multirow[t]{2}{*}{ Response } & \multicolumn{2}{|c|}{ Pre-Test } & \multicolumn{2}{|c|}{ Post-Test } & \multirow[t]{2}{*}{ p-value } \\
\hline & & $n$ & Valid Percent & $n$ & Valid Percent & \\
\hline \multirow{2}{*}{$\begin{array}{l}\text { Q1 } \\
\text { Have you ever heard of } \\
\text { electronic cigarettes/ e- } \\
\text { cigarettes/vapes? }\end{array}$} & No & 3 & 1.7 & 1 & 0.6 & \multirow[t]{2}{*}{.500} \\
\hline & Yes & 171 & 98.3 & 166 & 99.4 & \\
\hline \multirow{3}{*}{$\begin{array}{l}\text { Q2 } \\
\text { How did you learn about } \\
\text { the electronic } \\
\text { cigarettes/e- } \\
\text { cigarettes/vapes? }\end{array}$} & Media & 97 & 56.1 & 104 & 62.3 & \multirow[t]{3}{*}{.012} \\
\hline & & & & & & \\
\hline & Other & 76 & 43.9 & 63 & 37.7 & \\
\hline \multirow{2}{*}{$\begin{array}{l}\text { Q5 } \\
\text { Are electronic } \\
\text { cigarettes/e-cigarettes/ } \\
\text { vapes safer to use than } \\
\text { regular cigarettes? }\end{array}$} & No & 126 & 74.1 & 151 & 89.9 & \multirow[t]{2}{*}{.000} \\
\hline & Yes & 44 & 25.9 & 17 & 10.1 & \\
\hline
\end{tabular}




\begin{tabular}{|c|c|c|c|c|c|c|}
\hline \multirow[t]{2}{*}{ Variable } & \multirow[t]{2}{*}{ Response } & \multicolumn{2}{|c|}{ Pre-Test } & \multicolumn{2}{|c|}{ Post-Test } & \multirow[t]{2}{*}{ p-value } \\
\hline & & $n$ & Valid Percent & $n$ & Valid Percent & \\
\hline \multirow{2}{*}{$\begin{array}{l}\text { Q6 } \\
\text { Electronic cigarettes/e- } \\
\text { cigarettes/vapes may } \\
\text { lead to "regular" } \\
\text { cigarette smoking. }\end{array}$} & No & 39 & 22.8 & 29 & 17.4 & \multirow[t]{2}{*}{.286} \\
\hline & Yes & 132 & 77.2 & 138 & 82.6 & \\
\hline \multirow{2}{*}{$\begin{array}{l}\text { Q7 } \\
\text { Is vaping a health } \\
\text { problem in America? }\end{array}$} & No & 21 & 12.4 & 18 & 10.9 & \multirow[t]{2}{*}{.815} \\
\hline & Yes & 149 & 87.6 & 147 & 89.1 & \\
\hline \multirow{2}{*}{$\begin{array}{l}\text { Q8 } \\
\text { Should electronic } \\
\text { cigarettes/e- } \\
\text { cigarettes/vapes be } \\
\text { allowed in schools and } \\
\text { public places? }\end{array}$} & No & 133 & 78.2 & 134 & 80.7 & \multirow[t]{2}{*}{.727} \\
\hline & Yes & 37 & 21.8 & 32 & 19.3 & \\
\hline
\end{tabular}

